\title{
Atributos físicos e químicos do solo de Áreas sob Pastejo na Micro Região do Brejo Paraibano
}

\author{
Physical and chemical attributes of the soil under grazing Areas of the Region of \\ Micro Swamp Paraibano
}

\author{
Jussara Telma dos Santos ${ }^{\mathrm{I}}$ Albericio Pereira de Andrade ${ }^{\mathrm{I}}$ Ivandro de França da Silva $^{\mathrm{II}}$ \\ Divan Soares da Silva ${ }^{I}$ Edson Mauro Santos ${ }^{I}$ Ana Paula Gomes da Silva
}

\section{RESUMO}

O aumento da intensidade do uso do solo e a diminuição da cobertura vegetal nativa no nordeste brasileiro têm levado à degradação dos recursos naturais e, em especial, à diminuição da fertilidade do solo. Diante disso, o presente trabalho objetivou avaliar as mudanças nos atributos fisicos $e$ químicos do solo em área de floresta nativa secundária e pastagem na microrregião do Brejo Paraibano. Foram selecionadas três áreas, na propriedade Engenho Mineiro, cujo solo local foi classificado como Argissolo Vermelho Amarelo, sendo duas representadas por pastagens de capim Brachiaria ssp, exploradas por mais de 25 anos e com claros sinais de degradação, e a outra em área de floresta nativa secundária. $O$ delineamento utilizado foi o inteiramente casualizado no esquema de parcelas subdivididas com cinco repetições. As amostras de solo foram coletadas de 0-10, 10-20 e 20-30cm de profundidade. Em virtude do desnivel da área, procedeu-se às coletas numa linha em curva de nivel, distanciadas $10 \mathrm{~m}$ entre si. Os atributos físicos avaliados foram: densidade do solo e de partículas, porosidade total, argila total e natural, grau de floculação, diâmetro médio ponderado de agregado seco e úmido e determinação da distribuição de macro e micro agregados, separados por via seca e via úmida. Para os atributos quimicos, foram determinados os valores de $\mathrm{pH}$ em água e os teores de cálcio, magnésio, fósforo, potássio, aluminio trocável, hidrogênio + alumínio e de matéria orgânica (MO), para as áreas e profundidades estudadas. $O$ solo das áreas estudadas, em geral, apresentou baixa fertilidade. Dos resultados, verificou-se que mudanças na cobertura original acarretaram aumento no $\mathrm{pH}$ e redução no teor de matéria orgânica. A área cultivada com pastagem apresentou aumento dos valores de densidade do solo, densidade de partículas e diminuição da porosidade total, a mudança da cobertura vegetal influenciou nos valores de macro e micro agregados nos ambientes estudados. A utilização da segmentação da topossequência por posições no relevo, uso e profundidades, visando à determinação da degradação do solo, mostrou-se eficiente na avaliação das diferentes profundidades deste. O sistema de manejo utilizado ocasiona mudanças nos atributos físicos e químicos do solo, que contribuem para o processo de degradação da área.

Palavras-chave: brachiaria, compactação, degradação, estabilidade do agregado, fertilidade do solo, floresta secundária.

\section{ABSTRACT}

The increased intensity of land use and declining native vegetation in northeastern Brazil have led to degradation of natural resources and in particular to the decline of soil fertility. The present study aimed to assess changes in soil physical and chemical properties in secondary areas of native forest and pasture in the microregion of swamp Paraiban. Three areas were selected in the Engenho Mineiro property. whose land area was classified as Alfissol, and represented by pasture grass Brachiaria ssp which is being explorated for over 25 years with clear signs of degeneration and the other by a area of secondary native forest. The design was completely randomized in a split-plot with five replications. Soil samples were collected from $0-10,10-20$ and $20-30 \mathrm{~cm}$. Due to the unevenness of the area proceeded collect in line in curve level, $10.0 \mathrm{~m}$ apart from each other. The physical attributes evaluated were: bulk density and particle, total porosity, degree of flocculation, and totality native clay, degree of flocculation, aggregate dry and wet mean weight diameter and determination of the distribution of macro and micro aggregates separated by dry and wet. For the chemical attributes were determined $\mathrm{pH}$ values in water and calcium, magnesium, phosphorus, potassium, aluminum, hydrogen + aluminum, and organic matter (OM) for the areas and depths studied. The soils of, in general, showed low fertility. From the results, it

'Departamento do Centro de Ciências Agrárias (CCA), Universidade Federal da Paraiba (UFPB), Rodovia PB 079, Km 12, Campus II, 58397-000, Areia, PB, Brasil. Email: sarathelma@yahoo.com.br. *Autor para correspondência.

II Departamento de Solos e Engenharia Rural, CCA, UFPB, Campus III, Areia, PB, Brasil. 
was found that changes in the the original coverage cause an increase in $\mathrm{pH}$ and reduction in organic matter content. The area cultivated with pasture presented higher values of soil density, density of particles and reduction of total porosity. The change in the vegetation cover influenced the values of macro and micro aggregates in the studied environments. The use of segmentation by the toposequence positions in the landascape, use and depths, to the determine soil degradation, was efficient in evaluating the different depths of it. The management system used causes changes in the soil physical and chemical attributes that contribute to the process of soil degradation.

Key words: Brachiaria, compaction, degradation, stability of household, secondary forest, soil fertility.

\section{INTRODUÇÃO}

A produção animal, baseada no uso de pastagens, consiste em uma das alternativas mais competitivas e rentáveis da pecuária brasileira. No entanto, para que os benefícios aconteçam, faz-se necessário compreender que o manejo solo/planta/ animal é condição necessária para não levar ao estágio de degradação das áreas sob pastagens. O processo de degradação da pastagem é fenômeno complexo que envolve causas e consequências primárias e secundárias, que levam à gradativa diminuição da capacidade de suporte da pastagem, afetam a produção e o desempenho animal, causando a degradação do solo e dos recursos naturais, em função de manejos inadequados (DIAS-FILHO, 2005).

A história do município de Areia, no Brejo Paraibano, foi construída inicialmente com base na exploração da cana-de-açúcar, que, após colapso nesse sistema de produção, culminou com a exploração agropecuária. Em ambos os casos, os cuidados e atenções com o ambiente foram negligenciados e o quadro atual é formado por severos impactos, destacados pela presença de variados processos degradador. Dessa forma, são necessários estudos que caracterizem as alterações físicas e químicas dos solos sob pastagens, cuja finalidade seja o entendimento das modificações que sofrem os solos após a retirada da vegetação original para o estabelecimento da pastagem. Para DIAS-FILHO (2007), a degradação de uma área verifica-se pela diminuição da sua vegetação, provocada pela deterioração do solo, que, por diversas razões de natureza química, física ou biológica, estaria perdendo a capacidade de sustentar a produção vegetal de forma significativa. Diante do exposto, objetivouse com esse trabalho diagnosticar as alterações nas propriedades físicas e químicas do solo em área de pastagem e de floresta nativa secundária na microrregião do Brejo Paraibano, buscando indicadores que possam ser utilizados para orientar o manejo sustentável das terras para a produção pecuária.

\section{MATERIAL E MÉTODOS}

A pesquisa foi realizada na Fazenda Engenho Mineiro, no Município de Areia, localizado na microrregião do Brejo Paraibano, no ano de 2008. A área pertence ao domínio do Bioma Mata atlântica, cujo clima regional, de acordo com a classificação de Köppen, é do tipo As' (quente úmido com chuvas de outono inverno), com precipitação pluvial média anual de $1.500 \mathrm{~mm}$, com relevo variando de ondulado a fortemente ondulado, localizada entre as coordenadas geográficas: $6^{\circ} 57^{\prime} 46^{\prime \prime} \mathrm{S}, 35^{\circ} 41^{\prime} 31^{\prime \prime} \mathrm{W}$ de Greenwich, com altitude variando entre $400 \mathrm{~m}$ e $600 \mathrm{~m}$, umidade relativa em torno de $85 \%$. O solo local foi classificado por BRASIL (1972), enquadrando-se na nova classificação proposta por EMBRAPA (2006), como Argissolo Vermelho Amarelo. A topografia é constituída, na sua maioria, por terrenos acidentados em relevo forte ondulado a montanhoso, com declividade acentuada.

As áreas estudadas foram representadas por áreas de pastagem constituídas de capim (Brachiaria decumbens $\mathrm{L}$.) e floresta nativa secundária, as quais apresentam as mesmas características edáficas, cujo potencial produtivo do solo estava comprometido em decorrência da falta de manejo adequado, como correção e fertilização do solo, conforme histórico local. Foram selecionadas três áreas (mata nativa $-\mathrm{MN}$, pastagem semi-degradada - PSD e pastagem degradada - PD) para avaliação dos atributos físicos e químícos do solo, distribuídas em diferentes posições dentro da propriedade, levando em consideração, para mensuração do estado de degradação, sinais visuais indicativos de áreas compactadas, tais como: pouca oferta de forragem, baixa cobertura do solo e a formação de crostas na superfície do solo. As áreas foram identificadas da seguinte forma: área 1: área sob Mata Nativa Secundária, localizada no lado Norte da propriedade, em relevo suave ondulado, cuja vegetação apresenta-se como um mosaico formado por floresta e capoeira, destinado à preservação; área 2 , localizada no lado Leste da propriedade, em relevo forte ondulado, caracterizada visualmente como em processo intermediário de degradação (semi-degradada), com formação de pastagens, com poucos espaços em processo de degradação (declínio de oferta de forragem e vários tipos de plantas, arbóreas, arbustivas e invasoras); área 3, localizada no lado Oeste da propriedade, a $200 \mathrm{~m}$ da segunda área, relevo forte ondulado. Foi considerada visualmente em estado avançado de degradação, pois foi observado que o solo estava exposto, com pouca ou nenhuma vegetação e formação de encrostamento (inexistência do horizonte 
"A"), baixa cobertura de solo e processos erosivos acentuados.

Seguindo uma transecção linear, foram amostrados cinco pontos em três posições do relevo, em cada área, sendo coletadas amostras de solos em três profundidades $(0-10,10-20$ e $20-30 \mathrm{~cm})$. A amostragem consistiu na abertura de uma trincheira, em cada ponto, onde se procedeu à amostragem de aproximadamente $2,0 \mathrm{~kg}$ de solo para cada profundidade. As determinações físicas do solo foram realizadas no Laboratório de Física do Solo da UFPB, após secagem das amostras, consistindo de: argila total e natural e grau de floculação; densidade do solo e de partículas; porosidade total, todas de acordo com metodologias contidas em EMBRAPA (1997); diâmetro médio ponderado e estabilidade de agregados em água, conforme metodologias de TISDALL et al. (1978) e SILVA\& MIELNICZUK (1997). As Análises químicas foram realizadas no Laboratório de Química do Solo no Departamento de Solos e Engenharia Rural do CCAUFPB. Foram determinados os valores de $\mathrm{pH}$ em água e os teores de cálcio, magnésio (solução:extrator), sódio, alumínio trocável, hidrogênio + alumínio, fósforo, potássio e de matéria orgânica. As análises descritas estão de acordo com os métodos contido no Manual de Métodos de Análise de Solo descrita por EMBRAPA (1997).
A análise estatística dos dados foi realizada em parcela subdividida, sendo os tratamentos considerados como parcelas e as três profundidades, $0-10 \mathrm{~cm} ; 10-20 \mathrm{~cm} ; 20-30 \mathrm{~cm}$ e $60-80 \mathrm{~cm}$, como subparcelas com 5 repetições, totalizando 45 unidades experimentais por área. Foi realizada análise da variância e os resultados obtidos foram analisados por meio da comparação das médias dos valores dos atributos do solo nas duas áreas avaliadas, bem como nas três profundidades de solo. A comparação entre as médias dos tratamentos foi realizada pelo teste de Tukey $(\mathrm{P}<0,05)$, utilizando o programa SAS 2001.

\section{RESULTADOS E DISCUSSÃO}

Houve diferença significativa $(\mathrm{P}<0,05)$ entre as áreas para densidade do solo (Ds) e de partículas (Dp) e porosidade total do solo, teores de argila e grau de dispersão sob condições de pastagem e mata (Tabela 1). Os valores mais baixos da Ds na área de Mata Nativa (MN) se deve ao fato de essa área encontrar-se em boas condições, com maior diversidade biológica, maior teor de matéria orgânica, que é caracterizado como um dos fatores responsáveis pela manutenção das condições físicas do solo e que também tem mais influência na reversão do estado de compactação do solo, como relatam ASSOULINE et al.

Tabela 1 - Valores de densidade do solo, densidade de partículas e porosidade total, para as condições de mata nativa e pastagem, nas diferentes profundidades.

\begin{tabular}{|c|c|c|c|c|c|c|}
\hline \multirow[b]{2}{*}{ Profundidade } & \multicolumn{2}{|c|}{ Densidade } & \multirow[b]{2}{*}{ Porosidade total } & \multirow[b]{2}{*}{ Argila total } & \multirow[b]{2}{*}{ Argila natural } & \multirow[b]{2}{*}{ Grau de floculação } \\
\hline & Sol & Dostín & & & & \\
\hline $\mathrm{cm}$ & \multicolumn{2}{|c|}{ 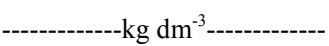 } & $\mathrm{m}^{3} \mathrm{~m}^{3}$ & \multicolumn{3}{|c|}{ 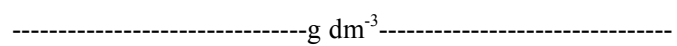 } \\
\hline \multicolumn{7}{|c|}{ - } \\
\hline $0-10$ & $1,26 \mathrm{Aa}$ & $2,65 \mathrm{Ba}$ & $0,52 \mathrm{Ab}$ & $407 \mathrm{Ca}$ & 34Aa & 916Aa \\
\hline $10-20$ & $1,31 \mathrm{Aa}$ & $2,66 \mathrm{Ba}$ & $0,50 \mathrm{Bab}$ & $408 \mathrm{Ca}$ & $33 \mathrm{Aa}$ & $918 \mathrm{Aa}$ \\
\hline $20-30$ & $1,36 \mathrm{Aa}$ & $2,69 \mathrm{Ba}$ & $0,48 \mathrm{Ba}$ & $399 \mathrm{Ca}$ & 29Aa & $926 \mathrm{Aa}$ \\
\hline \multicolumn{7}{|c|}{-Pemi-Degradada (PSD) --- } \\
\hline $0-10$ & $1,43 \mathrm{Ba}$ & $2,64 \mathrm{Ba}$ & $0,46 \mathrm{Ba}$ & $506 \mathrm{Ab}$ & $92 \mathrm{Ba}$ & $817 \mathrm{Bb}$ \\
\hline $10-20$ & $1,36 \mathrm{Aa}$ & $2,67 \mathrm{Ba}$ & $0,49 \mathrm{Bab}$ & $566 \mathrm{Aa}$ & $85 \mathrm{Ba}$ & $847 \mathrm{Bab}$ \\
\hline $20-30$ & $1,36 \mathrm{Aa}$ & $2,68 \mathrm{Ba}$ & $0,50 \mathrm{Bb}$ & $594 \mathrm{Aa}$ & $75 \mathrm{Ba}$ & $871 \mathrm{Ba}$ \\
\hline \multicolumn{7}{|c|}{ Pastagem Degradada (PD) --- } \\
\hline $10-20$ & $1,37 \mathrm{Aa}$ & $2,67 \mathrm{Ba}$ & $0,49 \mathrm{Bb}$ & $526 \mathrm{Ba}$ & $37 \mathrm{Aa}$ & 928Aab \\
\hline $20-30$ & $1,34 \mathrm{Aa}$ & $2,68 \mathrm{Ba}$ & $0,50 \mathrm{Bb}$ & $559 \mathrm{Ba}$ & $29 \mathrm{Aa}$ & 948Aa \\
\hline CV (\%) & 6,27 & 2,41 & 6,96 & 10,53 & 37,35 & 4,60 \\
\hline
\end{tabular}

MN - Mata Nativa; PSD - Pastagem Semi-Degradada; PD - Pastagem Degradada.

Médias seguidas pela mesma letra maiúscula nas linhas e minúscula nas colunas não diferem entre si, para a profundidade e sistema de uso, respectivamente, pelo teste de Tukey, a 5\% de probabilidade.

Ciência Rural, v.40, n.12, dez, 2010. 
(1997), CAMARGOe ALLEONI(1997)e DIAS JÚNIOR et al. (1999). Já os valores mais elevados de Ds para as camadas superficiais das áreas de pastagem são consequência provável de maior tráfego dos animais, mau manejo do solo por excesso de pastejo e outras modalidades de pressão, que favoreceram a maior compactação, conforme declaram SILVA 2000), FRAGA \& SALCEDO (2004). O pisoteio animal pode ocasionar, além do aumento da Ds, alteração na estabilidade dos agregados pela desagregação ou desestruturação dos agregados, proporcionada pelo uso permanente dos animais nas áreas de pastejo, cujo efeito da compactação é potencializado nos períodos de maior umidade. FREGONEZI et al. (2001) concluíram que o efeito do preparo intensivo e queima dos resíduos, tráfego intenso, impacto das gotas de chuvas, dispersão química dos colóides, inaptidão agrícola, atinge a estrutura do solo com consequências negativas sobre seus agregados, influenciando na taxa de infiltração de água . Pode-se afirmar que quanto mais elevada for à Ds, maior será a sua compactação, menor sua estruturação e sua porosidade total, tendo como consequência maior restrição para o crescimento e desenvolvimento das plantas. As variações entre os sistemas de uso e entre as profundidades podem ser relacionadas ao período de ocupação da área, à carga animal adotada e ao histórico de uso da terra.

Os valores de densidade de partículas (Dp) entre as três áreas não apresentam diferenças significativas (Tabela 1) nas áreas de pastagens. Os valores tenderam a ser mais elevados quando o uso se faz com o manejo inadequado do solo, pois, na produção que envolve pecuária, a degradação física, evidenciada na forma de compactação causada pelo pisoteio dos animais e também a ausência de revolvimento da camada superficial, pode comprometer a eficiência do sistema. A terra mantido em estado natural, sob vegetação nativa, preserva as características físicas adequadas ao desenvolvimento normal das plantas condições em que o volume de solo explorado pelas raízes é relativamente grande (ANDREOLA et al., 2000). Ainda na tabela 1, são apresentados os valores de porosidade total $(\mathrm{Pt})$ sob condições de pastagem e mata nativa. Os valores mais elevados de Pt na área de Mata Nativa deve-se ao fato de que possivelmente esse sistema esteja em equilíbrio e sem nenhuma atividade antrópica que possa levar a alguma alteração, corroborando os resultados apresentados por BERGAMIN et al. (2002). Esses autores relatam que a ausência da ação de máquinas e equipamentos, associada à elevada cobertura do solo e matéria orgânica na vegetação nativa, afeta de forma positiva as suas propriedades físicas. Dentre as propriedades físicas sujeitas a alterações pela presença de animais, principalmente aquelas relativas ao estado poroso, merecem especial atenção, pois é o local onde ocorrem os principais fenômenos que regulam o crescimento das plantas (SIQUEIRA JÚNIOR, 2005). Os teores de argila total e argila natural foram mais expressivos nas áreas de pastagens. Este aumento no teor de argila total e natural pode ser pela exposição do horizonte subuperficial, consequência do processo erosivo intenso, pelo manuseio que este solo recebeu ou ao nível de inclinação do terreno, pois as partículas mais grossas estão sendo carreadas e ficando material mais fino nas camadas subsuperficiais. Essa informação está em concordância com FULLER et al. (1995), que observaram a alteração no conteúdo de eluviação da argila com manejo intenso do solo cultivado com canade-açúcar.

Com relação aos graus de floculação, os menores valores na pastagem semi-degradada, indicam maior vulnerabilidade deste solo à erosão hídrica, caso encontre-se sem cobertura vegetal. Os maiores teores de grau de floculação, nas camadas internas das áreas de mata nativa e de pastagem degradada, contribuiem para menor dispersão da argila em água, o que é uma característica desejável. Pode ser atribuída ainda a presença de gramíneas nas áreas de pastagens, relacionado ao maior aporte de raízes da braquiária, as quais promovem maior agregação das partículas pelo efeito mecânico e provavelmente pela decomposição da matéria orgânica e por exsudatos de raízes (OADES, 1984). Na tabela 2, comparando os dados do DMPAu com os valores de DMPAs, observa-se que tanto DMPAu como DMPAs, para áreas de pastagens e área de mata, apresentam valores elevados, demonstrando alta estabilidade dos agregados, uma vez que os agregados secos (DMPAs) foram pouco alterados quando submetido à peneiragem úmida (DMPAu). Esse maior efeito de gramíneas na agregação do solo ocorre, segundo SILVA\& MIELNICZUK (1997), devido à maior densidade das raízes, às periódicas renovações do sistema radicular, e à uniforme distribuição dos exsudatos no solo, que estimulam a atividade microbiana, promovendo maior agregação.

Quanto à distribuição de macro e microagregados secos e úmidos, verifica-se, na comparação dos valores, uma redução dos macroagregados e um aumento dos microagregados, demonstrando que os agregados secos, ao serem umedecidos, desintegram-se e aumenta a percentagem de microagregados úmidos. Os menores valores de macroporosidade geralmente são devido ao processo de compactação da superfície do solo. Com a compactação do solo, esses poros sofrem uma maior 
Tabela 2 - Valores da argila total, argila natural e grau de floculação, para as condições de mata nativa e pastagem, nas diferentes profundidades.

\begin{tabular}{|c|c|c|c|c|c|c|c|}
\hline \multirow{2}{*}{ Profundidade } & \multicolumn{2}{|c|}{ DMPA } & \multirow{2}{*}{ DMPAu/DMPAs } & \multicolumn{2}{|c|}{ Via Seca } & \multicolumn{2}{|c|}{ Via Úmida } \\
\hline & Seco & Úmido & & Macro & Micro & Macro & Micro \\
\hline $\mathrm{cm}$ & \multicolumn{7}{|c|}{ 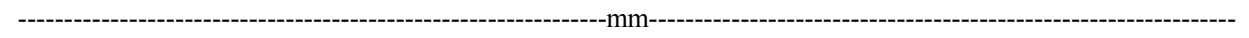 } \\
\hline $0-10$ & $3,62 \mathrm{Ca}$ & 2,77Aa & $0,773 \mathrm{Aa}$ & $96,7 \mathrm{Ba}$ & $3,26 \mathrm{Ba}$ & $88,6 \mathrm{Aa}$ & $11,4 \mathrm{Aa}$ \\
\hline $10-20$ & $3,53 \mathrm{Ca}$ & $2,75 \mathrm{Aa}$ & $0,772 \mathrm{Aa}$ & $96,8 \mathrm{Ba}$ & $3,22 \mathrm{Ba}$ & $86,8 \mathrm{Aa}$ & $13,2 \mathrm{Aa}$ \\
\hline $20-30$ & $3,55 \mathrm{Ba}$ & $2,54 \mathrm{Aa}$ & $0,715 \mathrm{Aa}$ & $96,6 \mathrm{Ba}$ & $3,34 \mathrm{Ba}$ & $87,0 \mathrm{Aa}$ & $13,0 \mathrm{Aa}$ \\
\hline & & & tagem Semi-Degr & (PSD) --- & & & \\
\hline $0-10$ & 3,99Aa & $2,63 \mathrm{Aa}$ & $0,659 \mathrm{Ba}$ & $98,7 \mathrm{Aa}$ & $1,28 \mathrm{Aa}$ & $84,5 \mathrm{Ba}$ & $15,5 \mathrm{Ba}$ \\
\hline $10-20$ & $3,96 \mathrm{Aa}$ & $2,31 \mathrm{Ba}$ & $0,586 \mathrm{Bab}$ & $98,6 \mathrm{Aa}$ & $1,40 \mathrm{Aa}$ & $82,1 \mathrm{Bab}$ & $17,9 \mathrm{Ba}$ \\
\hline $20-30$ & $3,86 \mathrm{Aa}$ & $1,91 \mathrm{Bb}$ & $0,494 \mathrm{Cb}$ & $98,2 \mathrm{Aa}$ & $1,77 \mathrm{Aa}$ & $80,4 \mathrm{Bb}$ & $19,6 \mathrm{Ba}$ \\
\hline & & & -Pastgem Degrada & D) ------- & & $\cdots$ & ---------- \\
\hline $0-10$ & $3,37 \mathrm{Ba}$ & $2,66 \mathrm{Aa}$ & $0,788 \mathrm{Aa}$ & $95,8 \mathrm{Ba}$ & $4,17 \mathrm{Ba}$ & $85,7 \mathrm{ABa}$ & $14,3 \mathrm{ABa}$ \\
\hline $10-20$ & $3,39 \mathrm{Ba}$ & $2,35 \mathrm{Bab}$ & $0,693 \mathrm{Ab}$ & $95,7 \mathrm{Ba}$ & $4,33 \mathrm{Ba}$ & $83,3 \mathrm{ABab}$ & $16,7 \mathrm{ABab}$ \\
\hline $20-30$ & $3,36 \mathrm{Ba}$ & $2,08 \mathrm{Bb}$ & $0,621 \mathrm{Bb}$ & $95,2 \mathrm{Ba}$ & $4,80 \mathrm{Ba}$ & $80,7 \mathrm{Bb}$ & $19,3 \mathrm{Bb}$ \\
\hline CV (\%) & 10,41 & 16,66 & 15,98 & 1,80 & 56,99 & 5,19 & 28,02 \\
\hline
\end{tabular}

MN - Mata; PSD - Pastagem Semi-Degradada; PD - Pastagem Degradada.

Médias seguidas pela mesma letra maiúscula nas linhas e minúscula nas colunas não diferem entre si, para a profundidade e sistema de uso, respectivamente, pelo teste de Tukey, a $5 \%$ de probabilidade.

redução, podendo ocorrer aumento dos microporos, reduzindo a porosidade total (Tabela 1), porém em menor proporção que a macroporosidade (ARAÚJO, 2004). Esses valores estão de acordo com os encontrados na PD, que apresentou maiores valores de microporosidade e menores de porosidade total, confirmando uma maior tendência à compactação do solo.

Observa-se que há diferença significativa para as variáveis $\mathrm{pH}$ e $\mathrm{MO}$, para as condições de mata e pastagem (Tabela 3). O pH dessas áreas apresenta acidez elevada $(\mathrm{pH}<5)$, no entanto, a área sob pastagem semi-degradada apresenta valores ligeiramente superiores na profundidade de $0-30 \mathrm{~cm}$, apresentando acidez média em relação às demais. Essa propriedade não influencia diretamente o desenvolvimento vegetal, exceto em casos extremos. Contudo, as condições resultantes dos baixos valores de $\mathrm{pH}$ podem limitar o desenvolvimento das plantas, tanto pelo efeito sobre a disponibilidade de nutrientes, como pela concentração de alumínio em níveis tóxicos para a planta, aumentada para valores de $\mathrm{pH}$ abaixo de 5,5, em que a solubilidade deste elemento aumenta abruptamente, afetando diretamente a eficiência da absorção de nutrientes pelas células das raízes da planta e, assim, atinge sua produtividade (MALAVOLTA, 1980; MARSCHNER, 1995). Solos ideais para cultivo devem apresentar $\mathrm{pH}$ entre 6,0 e 6,5; estando os solos de PSD mais próximos desses valores, que pode ter recebido a devida correção em período anterior a esse estudo.
Houve interação entre profundidade $(\mathrm{P}<0,05)$ em relação ao sistema de uso, para o atributo matéria orgânica (MO). Os dados indicam alto teor de matéria orgânica apenas na primeira camada da pastagem semi-degradada (PSD) e nas camadas supbsuperficiais da área de mata nativa (MN), o que confere distribuição da matéria orgânica mais uniforme nesse perfil, resultando em um solo mais estruturado e maior capacidade de retenção de água e nutrientes. A matéria orgânica que se acumula nos solos é resultante, principalmente, da decomposição dos resíduos vegetais depositados na superfície do solo e das raízes provenientes das plantas. Essa acumulação, porém, é mais acentuada nas camadas superficiais, como comprovado nas áreas de pastagens. De acordo com estudos realizados por PINHEIRO et al. (2004), a presença de gramíneas contribui para aumentos significativos da fração da matéria orgânica do solo e isso ocorre devido à elevada quantidade de palhada adicionada ao solo. Com o incremento do teor de matéria orgânica, há melhor distribuição de micro e macro poros do solo, favorecendo sua aeração e capacidade de infiltração e retenção de água. Além disso, há melhor estruturação e redução da densidade do solo, favorecendo a exploração de maior volume de solo pelas raízes (LONGO, 1994). SILVA et al. (2007) observaram que os valores de $\mathrm{MO}$ foram reduzindo à medida que $\mathrm{o}$ processo de sucessão ecológica mata-capoeirapastagem evoluía, evidenciando a importância da manutenção da vegetação nativa. 
Tabela 3 - Valores de $\mathrm{pH}$, matéria orgânica, Carbono, Fósforo $(\mathrm{P})$ e Potássio $(\mathrm{K})$, Cálcio + magnésio $\mathrm{Al}^{2+}$ e $\mathrm{H}^{+}+\mathrm{Al}^{2+}\left(\mathrm{cmol}^{2} \mathrm{dm}^{3}\right)$ determinados nas áreas sob mata nativa e pastagem, nas diferentes profundidades.

\begin{tabular}{|c|c|c|c|c|c|c|c|c|c|}
\hline \multirow{2}{*}{ Profundidade } & \multicolumn{9}{|c|}{ - } \\
\hline & $\mathrm{pH}$ & M.O & $\mathrm{C}$ & $\mathrm{P}$ & $\mathrm{K}$ & $\mathrm{Na}$ & $\mathrm{Ca}^{2-}+\mathrm{Mg}^{2-}$ & $\mathrm{Al}$ & $\mathrm{H}^{+}+\mathrm{Al}^{2+}$ \\
\hline $\mathrm{cm}$ & $1: 2,5$ & $\mathrm{~g} \mathrm{~kg}^{-1}$ & emol DM ${ }^{-1}$ & \multicolumn{3}{|c|}{$\mathrm{g} \mathrm{dm}^{-3}$} & \multicolumn{3}{|c|}{$\mathrm{cmol}_{\mathrm{c}} \cdot \mathrm{dm}^{-3}$} \\
\hline & & & - & Mata Nativ & $(\mathrm{MN})----$ & - & --------. & ---------- & ------ \\
\hline $0-10$ & $4,45 \mathrm{Bc}$ & $35,91 \mathrm{Ab}$ & $20,83 \mathrm{Ab}$ & $2,86 \mathrm{Aa}$ & $37,48 \mathrm{Aa}$ & $0,10 \mathrm{Aa}$ & $0,65 \mathrm{Ba}$ & $1,74 \mathrm{Ca}$ & $13,95 \mathrm{Cc}$ \\
\hline $10-20$ & $4,63 \mathrm{Ba}$ & $39,87 \mathrm{Aab}$ & $23,13 \mathrm{Aab}$ & $2,72 \mathrm{Aa}$ & $39,36 \mathrm{Aa}$ & $0,10 \mathrm{Aa}$ & $0,93 \mathrm{Ba}$ & $2,58 \mathrm{Cb}$ & $12,55 \mathrm{Bc}$ \\
\hline $20-30$ & $4,58 \mathrm{Bab}$ & $45,74 \mathrm{Aa}$ & $26,53 \mathrm{Aa}$ & $3,29 \mathrm{Aa}$ & $46,49 \mathrm{Aa}$ & $0,12 \mathrm{Aa}$ & $1,04 \mathrm{Ba}$ & $2,64 \mathrm{Ca}$ & $13,42 \mathrm{Cc}$ \\
\hline & & & ----Pasta & em Semi-D & gradada $(\mathrm{P}$ & 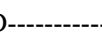 & & & ------ \\
\hline $0-10$ & $5,02 \mathrm{Ab}$ & $39,57 \mathrm{Aa}$ & $22,95 \mathrm{Aa}$ & $2,81 \mathrm{Aa}$ & $21,83 \mathrm{Ba}$ & $0,06 \mathrm{Ba}$ & $3,09 \mathrm{Aa}$ & $0,55 \mathrm{Aa}$ & 7,97Aa \\
\hline $10-20$ & $5,06 \mathrm{Aa}$ & $35,71 \mathrm{Aa}$ & $20,71 \mathrm{Aa}$ & $1,91 \mathrm{ABa}$ & $18,73 \mathrm{Ba}$ & $0,06 \mathrm{Ba}$ & $1,95 \mathrm{Aa}$ & $0,93 \mathrm{Ab}$ & $11,59 \mathrm{ABb}$ \\
\hline $20-30$ & 4,91Ac & $38,67 \mathrm{Ba}$ & $22,44 \mathrm{Ba}$ & $2,04 \mathrm{Ba}$ & $18,49 \mathrm{Ba}$ & $0,06 \mathrm{Ba}$ & $1,56 \mathrm{Ab}$ & $1,16 \mathrm{Ac}$ & $13,24 \mathrm{Cc}$ \\
\hline $0-10$ & $4,51 \mathrm{Ba}$ & $28,02 \mathrm{Ba}$ & $16,26 \mathrm{Ba}$ & $\begin{array}{c}\text { tagem Degr } \\
1,56 \mathrm{Ba}\end{array}$ & $\begin{array}{r}\text { dada (PD) } \\
23,85 \mathrm{Ba}\end{array}$ & $0,06 \mathrm{Ba}$ & $0,56 \mathrm{Ba}$ & $1,47 \mathrm{Ba}$ & $8,73 \mathrm{Ba}$ \\
\hline $10-20$ & $4,47 \mathrm{Ca}$ & $22,83 \mathrm{Ba}$ & $13,24 \mathrm{Ba}$ & $1,20 \mathrm{Ba}$ & $19,32 \mathrm{Ba}$ & $0,05 \mathrm{Ba}$ & $0,36 \mathrm{Ca}$ & $1,54 \mathrm{Ba}$ & $10,60 \mathrm{Ab}$ \\
\hline $20-30$ & $4,58 \mathrm{Ba}$ & $25,93 \mathrm{Ca}$ & $15,05 \mathrm{Ca}$ & $1,20 \mathrm{Ba}$ & $21,89 \mathrm{Ba}$ & $0,05 \mathrm{Ba}$ & $0,51 \mathrm{Ca}$ & $1,51 \mathrm{Ba}$ & $13,49 \mathrm{Cc}$ \\
\hline CV (\%) & 3,21 & 22,74 & 22,74 & 49,20 & 49,97 & 42,14 & 42,84 & 14,88 & 16,04 \\
\hline
\end{tabular}

MN - Mata; PSD - Pastagem Semi-Degradada; PD - Pastagem Degradada.

Médias seguidas pela mesma letra maiúscula nas linhas e minúscula nas colunas não diferem entre si, para a profundidade e sistema de uso, respectivamente, pelo teste de Tukey, a $5 \%$ de probabilidade.

A substituição das matas nativas pelo uso agropecuário levou a um empobrecimento generalizado dos solos, particularmente em relação aos teores $\mathrm{Ca}$, $\mathrm{Mg}, \mathrm{K}, \mathrm{Na}$ e C (Tabela 3), tendência observada também por outros autores (FRAGA \& SALCEDO, 2004). Isso pode resultar na perda de biodiversidade e na diminuição da capacidade dos ecossistemas de recuperar-se após perturbações. O risco de perda da fertilidade do solo é ainda maior no terço superior da encosta, como as linhas amostradas, onde há acentuação dos processos erosivos (SAMPAIO \& SALCEDO, 1997; SANTOS et al., 2002), principalmente quando a vegetação nativa é substituída por culturas agrícolas ou pastagens. Sendo assim, é recomendável a utilização de técnicas que minimizem os efeitos das alterações ocorridas nos atributos físicos e químicos do solo sob pastagem, na tentativa de corrigir os problemas decorrentes da compactação e fertilização. Nesse sentido, a descompactação ou reversão dos efeitos do pisoteio pode ser realizada por meio da utilização de uma taxa de lotação que permita uma produtividade em níveis sustentáveis, em longo prazo. Isso se dá devido ao fato de que a suscetibilidade à alteração do solo depende, entre muitas variáveis, da adequação do manejo, notadamente das práticas relacionadas aos atributos físicos dele. Uma melhor resposta pode ser obtida com a redução da densidade do solo e aumento da macroporosidade. Os baixos teores de nutrientes encontrados nas áreas estudadas são indicadores da baixa fertilidade natural desse solo.

\section{CONCLUSÃO}

Em relação à mata nativa, todas as áreas com pastagens apresentaram redução na qualidade do solo. $\mathrm{O}$ pisoteio dos animais favorece a compactação da camada superficial, em decorrência do aumento da sua densidade e da redução da porosidade total e macroporosidade

O material em estudo apresentou disponibilidade reduzida de nutrientes, considerável acidez, valores elevados de Al trocável e menores teores de matéria orgânica do solo que foi influenciada pelos sistemas de uso da terra conforme aumento da intensidade de uso. Alterações nos atributos físicos e químicos do solo podem ser utilizadas como um indicador auxiliar para o diagnóstico da degradação de áreas sob pastejo.

\section{REFERÊNCIAS}

ANDREOLA, F. et al. A cobertura vegetal de inverno e a adubação orgânica e, ou, mineral influenciando a sucessão feijão/ milho. Revista Brasileira de Ciência do Solo, v.24, n.4, p.867-874, 2000. Disponível em: <http://sbcs.solos.ufv.br/ solos/revistas/v24n4a18.pdf>. Acesso em: 27 set. 2010. doi: 10.1590/S0006-87052006000100016.

ARAÚJO, A.M. et al. Propriedades físicas de um latossolo vermelho distrófico cultivado e sob mata nativa. Revista Brasileira de Ciência do Solo, v.28, p.337-345, 2004. Disponível em: $<$ http://www.scielo.br/scielo.php?pid=S0100- 
$06832004000200012 \&$ script $=$ sci_abstract $\&$ tlng $=p t>$. Acesso em: 27 set, 2010. doi: 10.1590/S0100-06832004000200012.

ASSOULINE, S. et al. Effect of compaction on soil physical and hydraulic properties: experimental results and modling. Soil Science Society of America Journal, Madison, v.61, n.2, p.390-398, 1997.

BERGAMIN, E.M. et al. Alterações causadas pela pastagem e sistema agroflorestal na densidade do solo e porosidade total em Argissolo Vermelho distrófico na Amazônia. In: REUNIÃO BRASILEIRA DE MANEJO E CONSERVAÇÃO DO SOLO E DA ÁGUA, 14., 2002, Cuiabá. Anais... Cuiabá: Universidade Federal de Cuiabá, 2002. 1 CD-ROM.

CAMARGO, O.A.; ALLEONI, L.R.F. Compactação do solo e o desenvolvimento das plantas. Piracicaba: Esalq, 1997. 132p. Disponível em: <www.scielo.br/scielo.php?...S0100204X2004001100015>. Acesso em: 27 set, 2010. doi: 10.1590/S0100-204X2004001100015.

DIAS-FILHO, M.B. Degradação de pastagens: processos, causas e estratégias de recuperação. 3.ed. Belém: Embrapa Amazônia Oriental, 2007. 190p.

DIAS FILHO, M.B. Degradação de pastagens - processos, causas e estratégias de recuperação. 2.ed. Belém: Embrapa Amazônia Oriental, 2005. 173p.

DIAS JUNIOR, M.S. et al. Avaliação quantitativa da sustentabilidade estrutural dos solos em sistemas florestais na região de Aracruz-Es. Revista Árvore,v.23, n.4, p.371-380, 1999. Disponível em: $<$ http://www.scielo.br/scielo.php?pid=S 0100 $67622003000300010 \&$ script $=$ sci_arttext $>$. Acesso em: 27 set, 2010. doi: $10.1590 / \mathrm{S} 0100-67622003000300010$

EMBRAPA CNPS. Manual de métodos de análise de solos. Rio de Janeiro, 1997. 212p.

EMBRAPA. Centro Nacional de Pesquisa de Solos. Sistema brasileiro de classificação de solos. 2.ed. Rio de Janeiro, 2006. 306p.

FRAGA, V.S.; SALCEDO, I.H. Declines of organic nutrient pools in tropical semi-arid soils under subsystems farming. Soil Science Society of America Journal, v.68, n.1, p.215-224, 2004. Disponível em: <http://www.scielo.br/scielo.php?pid=S0100$67622010000200010 \&$ script $=$ sci_arttext\&tlng $=$ en $>$. Acesso em: 26 set, 2010. doi: 10.1590/S0100-67622010000200010.

FREGONEZI, G.A.F. et al. Modificações morfológicas e físicas de um Latossolo argiloso sob pastagens. Revista Brasileira de Ciência do Solo, v.25, p.1017-1027, 2001.

FULLER, L.G. et al. Cultivation effects on dispersible clay of soil aggregates. Canadian Journal of Soil Science, v.75, p. 101-107, 1995.

MALAVOLTA, E. Elementos de nutrição mineral de plantas. São Paulo: Ceres, 1980. 251p.

MARSCHNER, H. Mineral nutritition of higher plants. 2.ed. London: Academic, 1995. 889p.
OADES, J.M. Soil organic matter and structural stability: mechanisms and implications for management. Plant and Soil,v.76, p.319-337, 1984.

PINHEIRO, E.F.M et al. Fracionamento densimétrico da matéria orgânica do solo sob diferentes sistemas de manejo e cobertura vegetal em Paty do Alferes (RJ). Revista Brasileira de Ciência do Solo v.28, p.731-737, 2004. Disponível em: $<$ http://www.scielo.br/scielo.php? pid=S 0100 $06832008000200009 \&$ script $=$ sci_abstract\&tlng $=p t>$. Acesso em: 26 set, 2010. doi: 10.1590/S0100-06832008000200009.

SANTOS, A.C et al. Relação entre o relevo e as classes texturais do solo na microbacia hidrográfica de Vaca Brava, PB. Revista Brasileira de Cartografia, v.54, n.1, p.86-94, 2002. Disponível em: $<$ http://www.scielo.br/scielo.php?pid=S0100$67622010000200010 \&$ script $=$ sci_abstract\&tlng $=\mathrm{pt}>$. Acesso em: 27 set, 2010. doi: 10.1590/S0100-67622010000200010.

SANTOS, A.C. dos. Fertilidade do solo e redistribuição de $137 \mathrm{Cs}$ em função da cobertura vegetal, relevo e classes texturais, em uma microbacia hidrográfica do Estado da Paraíba. 2004. 67f. Tese (Doutorado em Tecnologias Energéticas e Nucleares) - Tecnologias Energéticas e Nucleares, Universidade Federal de Pernambuco, Recife, PE.

SAS INSTITUTE INC. System for Microsoft Windows. Release 6.12. Cary, NC, 2001. CD-ROM.

SILVA, I.F.; MIELNICZUK, J. Ação do sistema radicular de plantas na formação e estabilização de agregados do solo. Revista Brasileira de Ciência do Solo, v.20, p.113-117, 1997. Disponível em: <http://www.scielo.br/scielo.php?pid=S0100$06832004000500011 \&$ script $=$ sci_abstract $\&$ tlng $=p t>$. Acesso em: 27 set, 2010 . doi: $10.1590 / \bar{S} 0100-06832004000500011$.

SILVA, V.R. et al. Susceptibilidade à compactação de um Latosolo Vermelho-Escuro e de um Podzólico VermelhoAmarelo. Revista Brasileira de Ciência do Solo, v.24, n.2, p.239-249, 2000. Disponível em: <http://www.scielo.br/ scieloOrg/php/reflinks.php?refpid=S 1415 $4366201000080001000033 \& \mathrm{p}$ id $=\mathrm{S} 1415$ $43662010000800010 \& \operatorname{lng}=\mathrm{en}>$. Acesso em: 27 set, 2010. doi: $10.1590 / \mathrm{S} 1415-43662010000800010$.

SILVA, R.C.; et al. Alterações nas propriedades químicas e física de um Chernossolo com diferentes coberturas vegetais. Revista Brasileira de Ciência do Solo, v.31, p.101-107, 2007. Disponível em: <http://www.scielo.br/ scielo.php? script=sci_arttext \& pid = S $0100-$ 06832007000100011>. Acesso em: 27 set, 2010. doi: 10.1590/ S0100-06832007000100011.

SIQUEIRA JUNIOR. L.A. Alterações de características do solo na implantação de um sistema de integração agricultura-pecuaria leiteira. 2005. 107f. Dissertação, (Mestrado em agronomia) - Setor de Ciências Agrárias, Universidade Federal do Paraná, Curitiba,PR.

TISDALL, J.M. et al. The stability of soil aggregates as affected by organic materials microbial activity and physical disruption. Australian Journal of Soil Research v.16. p.9-17, 1978. 